\title{
Bioimpedance Vector Analysis (BIVA) for Diagnosis and Management of Acute Heart Failure
}

\author{
Salvatore Di Somma $\cdot$ Francesco Vetrone $\cdot$ \\ Alan S. Maisel
}

Published online: 27 March 2014

(C) Springer Science+Business Media New York 2014

\begin{abstract}
Acute heart failure (AHF) still represents one of the major reasons for hospitalization. AHF patients present with an increase in total body water (TBW) content, which is related to the disease severity. For emergency department physicians, a rapid assessment of the TBW can help in the diagnosis and management of these patients. Indeed, it is very important to identify patients with fluid overload to start prompt and adequate treatment. Furthermore, an exact identification of TBW and the monitoring of its variation from admission to discharge can help the physician to verify the efficacy of therapies and the patient's response. Different techniques already exist to evaluate patient fluid conditions, but new tools are emerging. Bioimpedance vector analysis allows better and more precise quantification of total body fluid contents. This article aims to describe the usefulness of BIVA in the management of AHF patients in the emergency department.
\end{abstract}

Keywords Acute heart failure - Dyspnea $\cdot$ Volume overload · Diagnosis - Emergency department . Bioimpedance vector analysis

S. Di Somma $(\varangle) \cdot$ F. Vetrone

Department of Medical-Surgery Sciences and Translational

Medicine, Emergency Department Sant'Andrea Hospital,

Postgraduate School of Emergency Medicine, University La

Sapienza, Rome, Italy

e-mail: salvatore.disomma@uniroma1.it

A. S. Maisel

Veterans Affairs San Diego Healthcare System, La Jolla Village

Drive, San Diego, CA 92122, USA

\section{Introduction}

Acute heart failure (AHF) is a common reason for patients to present to the emergency department (ED) and represents a diagnostic and therapeutic challenge for the emergency physician [1]. AHF is the single most common cause of hospitalizations in patients $>65$ years, accounting for $2 \%$ of all hospitalizations when it is the principal diagnosis and for $4 \%$ when recorded with other conditions [2, 3]. Moreover, in-hospital mortality rates, ranging from $4 \%$ [4] to $8 \%$ [5-8], are higher after discharge, reported to be from 8 to $15 \%$ by 3 months $[6,7,9,10]$, and are accompanied by frequent re-hospitalizations (30-38\% at 3 months) $[6,9,11,12]$.

AHF is characterized by a combination of clinical, hemodynamic, and neurohormonal abnormalities that lead to an increase in the total body water (TBW). In the healthy population, TBW is estimated to be approximately $60 \%$ of the body weight and is constantly adjusted by homeostatic mechanisms that include the balance between water intake and water loss via renal and gastrointestinal output, breathing and sweating. In AHF, these mechanisms are reflexively attenuated and contribute to an increase in congestive status, which is correlated with adverse events (death or re-hospitalization) at 3 months [13].

Because of the relationship between volume status and outcomes, the accurate and fast assessment of total fluid balance in critical patients is an important challenge for the emergency physician. The current gold standard (isotope dilution) is not used in emergency situations because of its inherent expense and the difficulty to obtain rapid results in the time-constrained environment of emergency clinical decision making [14]. In this important setting, several studies have confirmed the emergent role of biomarkers such as natriuretic peptides [15•], copeptin and bio- 
impedance vector analysis (BIVA) in the management of congestion in AHF patients. The aim of this article is to discuss the utility of non-invasive methods for hydration assessment.

AHF most frequently presents as a volume overload condition manifesting pulmonary congestion, hepatomegaly, ascites and peripheral edema. This hypervolemic condition is independently associated with high mortality $[16,17]$ and must be rapidly identified and treated to obtain optimal outcomes.

In AHF, a patient's cardiac dysfunction is characterized by reduced cardiac output and increased tissue congestion. Increased left ventricular filling pressure results in an elevated pulmonary capillary wedge pressure that may manifest as pulmonary edema, while increased right ventricular filling pressure results in rising systemic venous system pressures presenting as edema, jugular distension, hepatic congestion and ascites. In this condition the neurohormonal system is hyperactive, increasing renin-angiotensin-aldosterone activity and sympathetic nervous system tone, as well as resulting in increases in epinephrine, tumor necrosis factor, arginine vasopressin, interleukin- 6 and endothelin1. These neurohormonal abnormalities cause vasoconstriction and fluid retention, which perpetuate the cycle of worsening myocardial dysfunction, patient status and prognosis.

Because of the rapidity with which hemodynamic dysfunction can occur, delayed therapy in AHF has been associated with as much as a $150 \%$ increase in mortality. Conversely, the inappropriate use of diuretic therapy in non-AHF patients is also associated with an increase in mortality [18]. It is therefore critical that early intervention be targeted to the correct patient cohort. This is complicated by classification of AHF itself, in that while AHF patients can be classified into two groups, de novo or acute decompensated heart failure [19], they may present with underlying cardiac comorbidities such as coronary heart disease, hypertension, valvular heart diseases and atrial arrhythmias. Presentations may be further complicated by noncardiac conditions such as renal insufficiency, diabetes, anemia and chronic obstructive pulmonary disease, which may precipitate or contribute to worsening HF [20].

\section{TBW Assessment}

Currently, early AHF diagnosis and volume assessment are based on clinical judgment, laboratory tests, chest radiography, ultrasonography, invasive hemodynamic monitoring, and laboratory biomarkers (NP; natriuretic peptides) [21••]. While some clinical signs are common in AHF, such as pulmonary congestion, elevated jugular venous pulse, jugular venous congestion, third heart sound and edema, they may have limited utility because of poor sensitivity and specificity [22].

Although accurate volume assessment aids diagnostic accuracy and could help guide therapy and patient management [23], every currently available tool or technique that could help in identification of volume-overloaded patients needing diuretic therapy suffers from significant limitations.

\section{Clinical History}

Of data available at presentation, the patient's history is one of the most accurate for the diagnosis of AHF in the emergency department. Usually patients complain of shortness of breath, which may manifest as orthopnea or paroxysmal nocturnal dyspnea. In a meta-analysis by Wang et al. [22], they found that dyspnea on exertion had a good sensitivity but poor specificity, while paroxysmal nocturnal dyspnea, orthopnea and edema had high specificity but low sensitivity. These data suggest that clinical symptoms are useful in the diagnosis of overload volume due to congestive AHF, but sometimes are limited in providing discriminating information to the emergency physician.

\section{Physical Examination}

The physical examination provides some of the first information available the on clinical status of AHF patients with increased TBW. Unfortunately, some signs are not specific or sensitive, or are uncommon. For example, jugular venous distension and rales show a sensitivity between 37 and $70 \%$ and 24-66\%, respectively [19, 24, 25], while the third heart sound had a low sensitivity $(13 \%)$ but high specificity (99\%) [22]. Finally, in the RESOLVD trial, lower extremity edema was present in only $21 \%$ of patients with AHF and in only $10 \%$ of patients who were free of events [26]. It seems that further tools helping us in the diagnosis and management of AHF patients would be useful.

\section{Chest Radiography}

The chest radiograph is a standard test for assessing the fluid status of suspected AHF patients. Pulmonary congestion and volume overload may manifest with dilated upper-lobe vessels, cardiomegaly, interstitial edema, extended pulmonary artery, pleural effusion, alveolar edema and kerley lines [27]. However, chest radiography lacks sensitivity and accuracy in the diagnosis of AHF as demonstrated in an ADHERE registry analysis where $23.3 \%$ patients hospitalized with acute decompensated heart failure presented a negative chest X-ray [28, 29]. Furthermore chest X-ray evaluation depends on the type of radiograph, phase of inspiration and physician experience. 


\section{Ultrasonography}

Thoracic bedside ultrasound is a rapid and non-invasive imaging used for identifying interstitial and/or alveolar edema in AHF patients. The presence of lung water can be visualized by a sign called "lung comets" or "B-lines." Liteplo et al. [30] found, in 100 patients, that the presence of at least two of eight zones positive on each side of the thorax had a positive likelihood ratio for AHF of 3.88 (99 \% CI 1.55-9.73). This compared to a negative examination that had a negative likelihood ratio of 0.5 (99\% CI $0.30-0.82$ ). Another important part of fluid volume status ultrasound assessment is the evaluation of the inferior vena cava (IVC), which is considered a mirror of circulatory volume. This is demonstrated by the IVC, which is less collapsible in hypervolemia and more collapsible in hypovolemia, and it is assessed based on the measurement of the changes in vena cava diameter relative to inspiration and expiration.

Finally, the utility of bedside echocardiography is further supported by the American College of Cardiology/American Heart Association (ACC/AHA) guidelines. They state that echocardiography is the single most useful diagnostic test in the evaluation of patients with HF [31-33].

\section{Biomarkers}

Serum blood indices are commonly used for assessment of hydration status abnormalities. For example, changes in sodium concentration can contribute to assessing hydration status. Many biomarkers are new tools in the volume assessment of AHF patients [34••].

Natriuretic peptides are vasoactive neurohormones extensively used in the diagnosis, management and prognosis of HF. Natriuretic peptides, especially the 32-aminoacid active hormone, called $\mathrm{B}$ type natriuretic peptide (BNP), and the 76-amino-acid inactive form, named $\mathrm{N}$-terminal pro BNP (NT-pro BNP), have already been confirmed as useful biomarkers, not only for the differential diagnosis of dyspnea, but also for stratifying the risk in the ED, predicting death and re-hospitalization, and guiding therapy $[35,36]$. A cutoff value for BNP $<100 \mathrm{pg} / \mathrm{ml}$ (and $<400 \mathrm{pg} / \mathrm{ml}$ for NTPro BNP) is traditionally used to rule out cardiogenic dyspnea, whereas for to ruling it in, a cutoff value of BNP $>400 \mathrm{pg} / \mathrm{ml}$ (NT-Pro BNP $>2,000 \mathrm{pg} / \mathrm{ml}$ ) is used. Values of BNP between 100 and $400 \mathrm{pg} / \mathrm{ml}$ (or between 400 and $2,000 \mathrm{pg} / \mathrm{ml}$ for NT-Pro BNP) represent the "gray zone," thus requiring further analysis [37॰]. However, natriuretic peptide shows its measurement limitations in certain conditions, including renal dysfunction, obesity and atrial fibrillation.

The correlation between volume overload and BNP values is well studied. In a report of 49 hemodialysis patients, BNP levels were found to have a positive correlation among the ratios of extracellular fluid, TBW and IVC diameter [38]. Another study on 72 hemodialysis patients showed a correlation between NTpro-BNP and extracellular fluid [39].

\section{Bioimpedance Vector Analysis (BIVA)}

\section{Technique}

BIVA is a non-invasive, quick and inexpensive technique to estimate body composition [40]. This technique measures the opposition of body tissues to the flow of an alternating current of $800 \mu \mathrm{A}$ at an operating frequency of $50 \mathrm{kHz}$, called bioelectrical impedance [41]. This bioelectrical impedance $(Z)$ consists of two components, resistance $(R)$ and reactance $(\mathrm{Xc})$ [42, 43]. All biological structures have a specific resistance, defined as the strength of opposition by a tissue to the electric current flow. Fatfree tissues and fluids are good conductors, while bone and fat tissues are bad conductors, being electrically resistant. In terms of impedance, the human body can be schematically considered as a system composed of several conductors in parallel, which pass through two pathways: the extracellular tissue and intracellular membranes. In order to simplify the measurements, the human body is approximated as a sum of five interconnected cylinders that act as conductors in parallel and, while the resistance $(R)$ is inversely related to the amount of TBW, the reactance (Xc) is considered proportional to body mass $[44,45]$. Therefore the resistance is inversely related to the TBW, thus representing an indirect measure of the amount of body fluid.

BIVA is performed with a portable battery-operated device that can be applied in every critical setting requiring quick evaluation. For its measurement, the subject must be supine with (Fig. 1a) inferior limbs at $45^{\circ}$ and superior limbs abducted at $30^{\circ}$ to avoid skin contacts with the trunk and with the stretcher [44]. Four cutaneous electrodes, two on the wrist and two on the ipsilateral ankle, are applied with an inter-electrode distance of at least $5 \mathrm{~cm}$ to prevent interaction between electrodes (Fig. 1b). Free fluid in the thorax and abdomen, as pleural effusion, lung congestion, ascites, urine and food, does not influence impedance assessment measured by the BIVA technique [13].

The bioelectrical impedance is measured in about $30 \mathrm{~s}$, and the results can be displayed in two different modalities: as a vector or as a single number expressed in percentage in a specific scale (Fig. 2). The first method plots the two components $R$ and Xc on a graph to provide a vector whose length is proportional to TBW, and the angle above the $x$ axis (referred to as the phase angle) is reflective of cellular integrity. Reference values are adjusted for patient's age, 

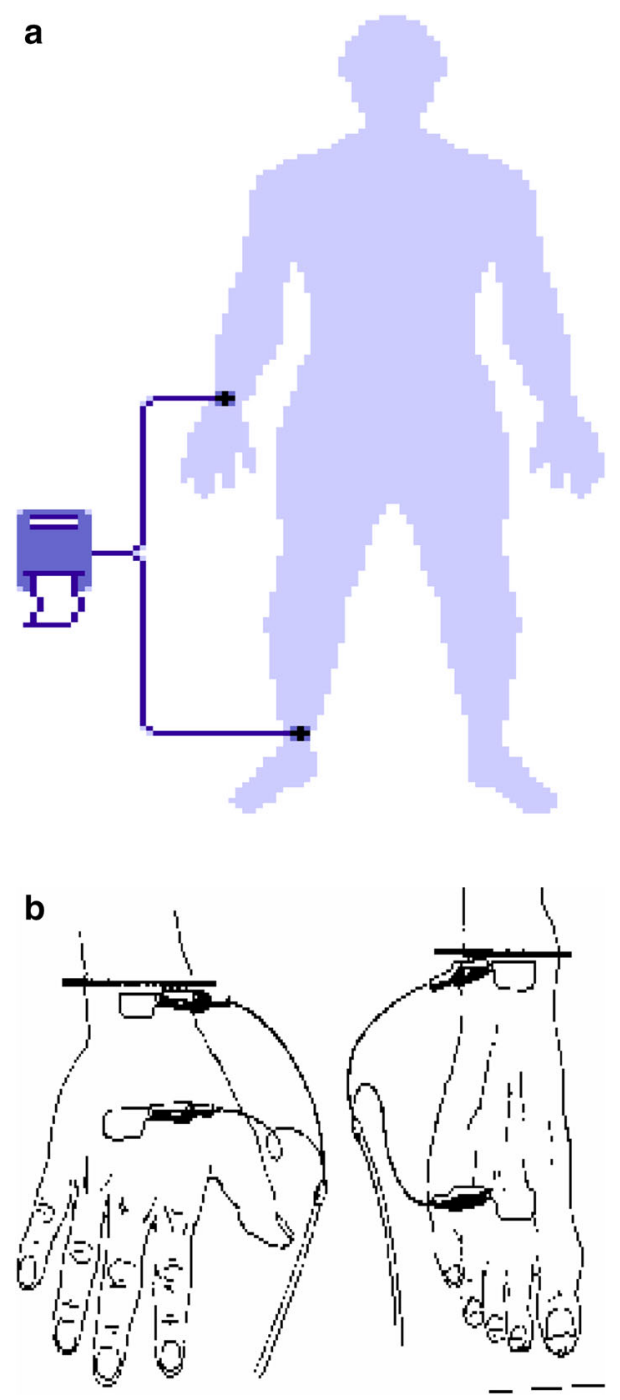

Fig. 1 a Subject's position. b Electrode application

body mass index, gender and height [46]. Three tolerance ellipses are plotted, corresponding to the 50th, 75th and 95th vector percentile of the healthy reference population of same sex and race. The major axis of this ellipses indexes hydration status, while the minor axis reflects tissue mass.

The second method expresses the state of hydration as a percentage in a scale called the hydrograph (or hydrogram). A normal value, corresponding to the 50th percentile, is included in the range between 72.7 and $74.3 \%$ [47].

BIVA results are very easy to interpret. As previously discussed, fluids are good conductors, so the length of vector, which represents the body's impedance, is inversely related to fluid volume. Moreover, several studies have agreed to defining the $75 \%$ tolerance ellipse as the boundary of normal volume status [42]. Consequently, vectors outside the upper pole of the $75 \%$ tolerance ellipse indicate dehydration, whereas vectors outside the lower

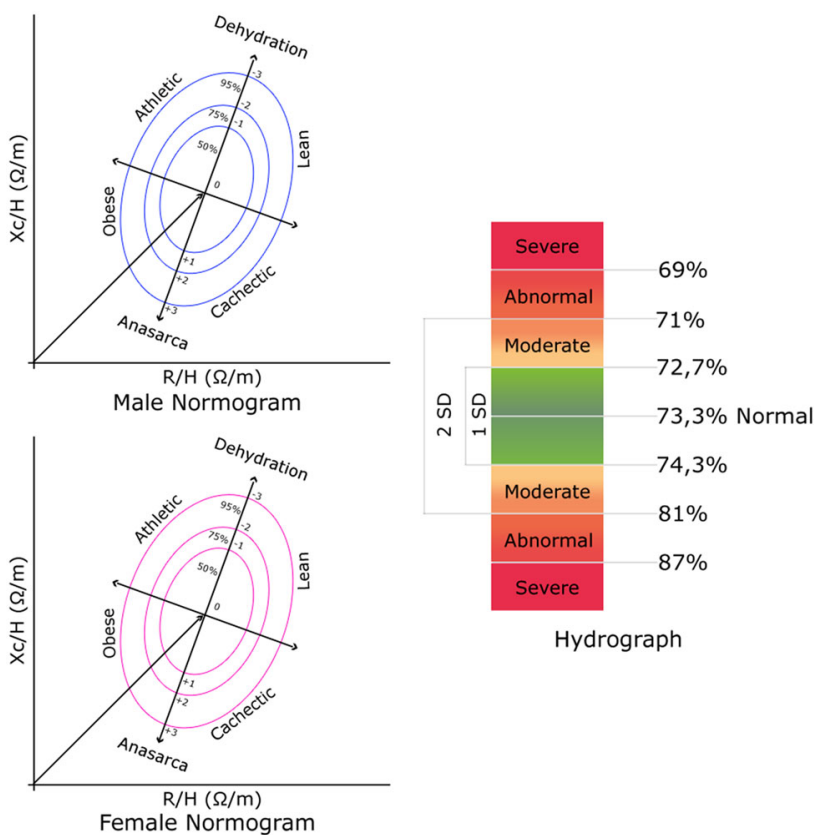

Fig. 2 BIVA results design

pole of the $75 \%$ tolerance ellipse represent overhydration or fluid overload. Thus, a short vector is associated with a fluid overload condition and edema [47, 48], while a longer one with a dehydration condition. However, several studies have suggested that the window of tolerance for hyper- or dehydration may vary in patients with different diseases [49••]. BIVA also allows the objective stratification of hydration status severity in both overhydration and dehydration patients by subdividing patients into mild, moderate or severe volume abnormalities [50].

\section{Role of BIVA in Clinical Practice: Management and Diagnosis}

Because several studies have demonstrated that the common signs and symptoms are not present in all patients with cardiogenic dyspnea [51], additional tools are necessary. Therefore, despite the unquestionable importance of clinical judgment, it seems BIVA may offer helpful information.

In the setting of undiagnosed dyspnea, a BIVA evaluation is an appealing perspective when applied in acute patients because it is specific to fluid overload. BIVA can help distinguish cardiogenic dyspnea from non-cardiogenic causes and, in combination with biomarker and clinical judgment, it is also useful for managing AHF patients, since both measures are helpful to drive emergency physicians' decisions about diuretic therapy and discharge [52••]. The importance is of emergency physicians being 
able to identify patients with congestive AHF in the first minutes has been demonstrated. In a study by Di Somma et al. [13], BIVA values were statistically different $(p<0.0007)$ between AHF patients and control groups. Indeed, AHF patients had a significantly higher hydration status value $(77 \% \pm 4)$ than controls $(73 \% \pm 2)$. Further, in this analysis, hydration assessment was evaluated at admission, 24 and $72 \mathrm{~h}$ later, and at discharge in AHF patients. Hydration evaluation was included in a multidimensional approach, using BIVA, natriuretic peptides, caval index and the measurement of the vascular pedicle width obtained by chest X-ray examination. The results confirmed the presence of a strong correlation between hyperhydration calculated by BIVA and central venous congestion and between hyperhydration and oliguria. Based on these data, it is possible to conclude that BIVA measurements are strictly related to the other three methods. The hydration index obtained by the BIVA and caval index showed a significant and indirectly proportional correlation at admission, after 24 and $72 \mathrm{~h}$ from hospital admission. Moreover, BIVA values change from a hyperhydrated state to a normally hydrated state related to the improvement of diuretic treatment in the AHF patient cohort. Furthermore, the efficacy of diuretic therapy and the validity of BIVA measurements were also confirmed by normalization of BNP, vascular pedicle width and caval index values at discharge [53]. The results of this study also proved the potential prognostic role of BIVA, showing a significant correlation of hydration values higher than $80 \%$ with events (death or re-hospitalization) at 3 months after admission [13]. Finally, other trials have shown that BIVA is predictive of volume status and outcomes independently from other variables [19, 49••, 54].

BIVA evaluation can be useful in distinguishing dyspnea causes. This was demonstrated by Piccoli in a study of 315 patients, where the impedance vector was shorter in cardiac dyspnea than in other-cause dyspnea [55•] (Fig. 3). Moreover, BIVA was also able to detect a "latent peripheral congestion." In another study by Piccoli, the association between BIVA and NT-proBNP was evaluated in patients with acute cardiac-related dyspnea. In the 'gray zone' of NT-proBNP values, BIVA detected latent peripheral congestion and thus helps emergency physicians in clinical decision making. Finally, in a pilot study on 54 ambulatory HF patients, BIVA was able to differentiate stable from non-stable HF patients with the combination of BIVA and NP results [42].

In addition to its diagnostic function, the combination of BIVA and BNP can identify patients with a higher probability of subsequent events (death or rehospitalization) and allows a more accurate risk stratification of patients undergoing diuretic therapy $[49 \bullet \bullet, 56 \bullet \cdot$. Using this knowledge, the BIVA technique can also be used to

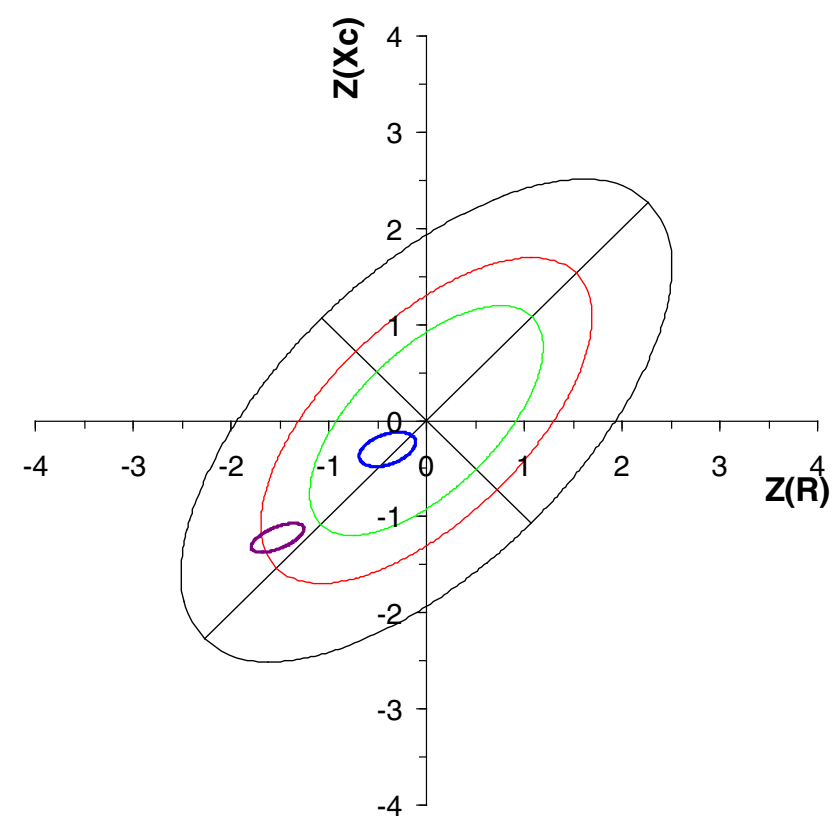

Fig. 3 Distribution of vectors by dyspnea. The blue ring represents patients with non-cardiogenic dyspnea, while the black one reflects the average of patients with cardiogenic dyspnea [55 $]$ (Color figure online)

manage and guide the therapy of AHF patients where it may be used to guide diuretic therapies by providing an accurate estimate of changes in TBW [57, 58]. In one study, it was demonstrated that a significant decrease in BIVA values occurs in AHF patients compared to a control group after $72 \mathrm{~h}$ of diuretic treatment and at discharge [13]. Furthermore, one study demonstrated that BIVA could determine the adequacy of ultrafiltration in more than 3,000 hemodialysis patients [59].

Some studies suggest that the role in decision making for AHF patients can be improved by using the combination of BIVA and BNP. One prospective study evaluated the diagnostic value of both in 292 dyspneic patients. Regression analyses performed separately for BIVA and BNP found both were strong predictors of AHF (C-statistic 0.934 and 0.970 , respectively), while the hydration status determination improved with the combination of BIVA and BNP (C-statistic 0.989) for identifying patients needing diuretic therapy [56•*]. This point has been addressed in multiple studies [60]. In one, Valle et al. [49*0] demonstrated that BIVA- and BNP-guided management during hospitalization for HF was associated with lower event rates after discharge, and this was independent of other prognostic variables. This combination of a multi-marker approach and fluid assessment has also been proposed in the management of ED patients with AHF and cardiorenal syndrome $[61,62 \cdot, 63 \bullet]$. 
BIVA may have utility in critically ill patients as well. In patients undergoing invasive hemodynamic monitoring, it has been demonstrated that BIVA measurements are related to the central venous pressure (CVP). In one study, CVP values were significantly and inversely correlated with individual impedance vector components $\left(r^{2}=0.28\right.$ and 0.27 with resistance and reactance, respectively) and with both vector components together $\left(r^{2}=0.31\right)$. Particularly, CVP values higher than $12 \mathrm{mmHg}$ were associated with shorter BIVA vectors in $93 \%$ of patients, reflecting overhydration. On the other hand, CVP values lower than $3 \mathrm{mmHg}$ were associated with longer vectors in $10 \%$ of patients, indicating dehydration. Moreover, the progressive increase in CVP values was associated with shorter and down-sloping impedance vectors on the nomogram [64]. These findings suggest that on the basis of this correlation, BIVA serial assessment could be used to drive therapy without the necessity of invasive monitoring.

\section{Conclusions}

In addition to the classical methods of diagnosis, such as clinical history, physical examination, ultrasonography, chest X-ray and natriuretic peptide, BIVA has proven to be a promising method for identifying congestive AHF in patients presenting with acute dyspnea.

The usefulness of BIVA in emergency conditions is further increased due to the fact that it is accurate, noninvasive, inexpensive, rapid and objective. Finally, BIVA demonstrates promise in its application to guide therapy and replace more invasive monitoring techniques.

\section{Compliance with Ethics Guidelines}

Conflict of Interest Alan Maisel reports receiving consulting fees, honoraria and research grants from Alere and BG Medicine. Francesco Vetrone and Salvatore Di Somma have reported no conflicts of interest.

Human and Animal Rights and Informed Consent This article does not contain any studies with human or animal subjects performed by any of the authors.

\section{References}

Recently published papers of particular interest have been highlighted as:

- Of importance

•- Of major importance

1. American Heart Association. Heart disease and stroke statistics: 2005 update. Dallas: American Heart Association; 2005.
2. McMurray J, McDonagh T, Morrison CE, et al. Trends in hospitalisation for heart failure in Scotland 1980-1990. Eur Heart J. 1993; 14:1158-62.

3. O'Connell JB, Bristow MR. Economic impact of heart failure in the United States: time for a different approach. J Heart Lung Transplant. 1994;13:S107-12.

4. Adams KF Jr, Fonarow GC, Emerman CL, et al. Characteristics and outcomes of patients hospitalized for heart failure in the United States: rationale, design, and preliminary observations from the first 100,000 cases in the Acute Decompensated Heart Failure National Registry (ADHERE). Am Heart J. 2005;149: 209-16.

5. Nieminen MS, Brutsaert D, Dickstein K, et al. EuroHeart Failure Survey II (EHFS II): a survey on hospitalized acute heart failure patients: description of population. Eur Heart J. 2006;27: 2725-36.

6. Tavazzi L, Maggioni AP, Lucci D, et al. Nationwide survey on acute heart failure in cardiology ward services in Italy. Eur Heart J. 2006;27:1207.

7. Rudiger A, Harjola V-P, Muller A, et al. Acute heart failure: clinical presentation, one-year mortality and prognostic factors. Eur J Heart Fail. 2005;7:662-70.

8. Lee DS, Austin PC, Rouleau JL, et al. Predicting mortality among patients hospitalized for heart failure: derivation and validation of a clinical model. JAMA. 2003;290:2581-7.

9. Cleland JG, Swedberg K, Follath F, et al. The EuroHeart Failure survey programme-a survey on the quality of care among patients with heart failure in Europe. Part 1: patient characteristics and diagnosis. Eur Heart J. 2003;24:442-63.

10. O'Connor CM, Stough WG, Gallup DS, et al. Demographics, clinical characteristics, and outcomes of patients hospitalized for decompensated heart failure: observations from the IMPACT-HF registry. J Card Fail. 2005;11:200-5.

11. Schaufelberger M, Swedberg K, Koster M, et al. Decreasing one year mortality and hospitalisation rates for heart failure in Sweden; data from the Swedish Hospital Discharge Registry 1988 to 2000. Eur Heart J. 2004;25:300-7.

12. Metra M, Dei Cas L, Bristow MR. The pathophysiology of acute heart failure-it is a lot about fluid accumulation. Am Heart J. 2008;155:1-5.

13. Di Somma S, De Berardinis B, Bongiovanni C, Marino R, Ferri E, Alfei B. Use of BNP and bioimpedance to drive therapy in heart failure patients. Congest Heart Fail. 2010;16:S56-61.

14. Peacock FW, Karina M, Soto MS. Current technique of fluid status assessment. Congest Heart Fail. 2010;16:45-51.

15. - Clerico A, Vittorini S, Passino C. Measurement of the prohormone of brain type natriuretic peptide (proBNP): methodological considerations and pathophysiological relevance. Clin Chem Lab Med 2011;49:1949-54. This review article discusses the methodological characteristics of specific hormones, such as pro-BNP and BNP. The kinetics and rapid assessment of these biomarkers allow their use in a emergency setting, especially with acute heart failure patients.

16. Maisel A, Mueller C, Adams K Jr, et al. State of the art: using natriuretic peptide levels in clinical practice. Eur J Heart Fail. 2008; 10:824-39.

17. Drazner MH, Rame JE, Stevenson LW, Dries DL. Prognostic importance of elevated jugular venous pressure and a third heart sound in patients with heart failure. N Engl J Med. 2001;345: 574-81.

18. Wuerz R, Meador S. Effects of prehospital medications on mortality and length of stay in congestive heart failure. Ann Emerg Med. 1992;21(6):669-74.

19. McMurray J, Adamopoulos S, Anker SD. ESC guidelines for the diagnosis and treatment of acute and chronic heart failure 2012. The task force for the diagnosis and treatment of acute and 
chronic heart failure 2012. of the European Society of Cardiology. Developed in collaboration with the Heart Failure Association (HFA) of the ESC. Eur Heart J. 2012;33:1787-847.

20. Gheorghiade M, Zannad F, Sopko G, et al. Acute heart failure syndromes current state and framework for future research. Circulation. 2005;112:3958-68.

21. •Di Somma S, Navarin S, Giordano S, Spadini F, Lippi G, Cervellin G, Dieffenbach BV, Maisel AS. The emerging role of biomarkers and bio-impedance in evaluating hydration status in patients with acute heart failure. Clin Chem Lab Med. 2012;50(12):2093-105. This review is important because it accurately describes the BIVA technique as well as its use in clinical practice and acute heart failure management. Furthermore, it compares different useful techniques (well known and new) to assess total body water, finding the BIVA technique of great utility in patients' water calculation.

22. Wang CS, FitzGerald JM, Schulzer M, et al. Does this dyspneic patient in the emergency department have congestive heart failure? JAMA. 2005;294:1944-56.

23. Jessup M, Abraham WT, Casey DE, Feldman AM, Francis GS, Ganiats TG, Konstam MA, Mancini DM, Rahko PS, Silver MA. 2009 focused update: ACCF/AHA guidelines for the diagnosis and Management of Heart Failure in Adults. A Report of the American College of Cardiology Foundation/American Heart Association Task Force on Practice Guidelines Developed in Collaboration with the International Society for Heart and Lung Transplantation. J Am Coll Cardiol. 2009;53(15):1343-82.

24. Butman SM, Ewy GA, Standen JR, Kern KB, Hahn E. Bedside cardiovascular examination in patients with severe chronic heart failure: importance of rest or inducible jugular venous distention. J Am Coll Cardiol. 1993;22:968-74.

25. Chakko S, Woska D, Martinez H, De Marchena E, Futterman L, Kessler KM, et al. Clinical, radiographic, and haemodynamic correlations in chronic congestive heart failure. Am J Med. 1991;90:353-9.

26. Tsuyuki RT, McKelvie RS, Arnold JM, Avezum AJ, Barretto $\mathrm{AC}$, Carvalho AC, et al. Acute precipitants of congestive heart failure exacerbations. Arch Intern Med. 2001;161:2337-42.

27. Chait A, Cohen HE, Meltzer LE, et al. The bedside chest radiograph in the evaluation of incipient heart failure. Radiology. 1972;105:563-6.

28. Collins SP, Lindsell CJ, Storrow AB, Abraham WT. Prevalence of negative chest radiography results in the emergency department patient with decompensated heart failure. Ann Emerg Med. 2006;47:13-8.

29. Milne EN, Pistolesi M, Miniati M, et al. The radiologic distinction of cardiogenic and noncardiogenic edema. AJR Am J Roentgenol. 1985;144:879-94.

30. Liteplo AS, Marill KA, Villen T, Miller RM, Murray AF, Croft $\mathrm{PE}$, et al. Emergency thoracic ultrasound in the differentiation of the etiology of shortness of breath (ETUDES): sonographic $\mathrm{B}$-lines and $\mathrm{N}$-terminal Pro-brain-type natriuretic peptide in diagnosing congestive heart failure. Acad Emerg Med. 2009;16:201-10.

31. Dickstein K, Choen-Solal A, Philippatos G, McMurray J, Ponikowski P, Poole-Wilson PA. ESC guidelines for the diagnosis and treatment of acute and chronic heart failure 2008. Eur J Heart Fail. 2008;10:933-89.

32. Kirkpatrick JN, Vannan MA, Narula J, Lang RM. Echocardiography in heart failure: applications, utility and new horizons. J Am Coll Cardiol. 2007;50:381-96.

33. Nguyen V, Ho J, Ho C, Givertz M, Stevenson L. Handheld echocardiography offers rapid assessment of clinical volume status. Am Heart J. 2008;156(3):537-42.
34. •• Choudhary R, Di Somma S, Maisel AS. Biomarkers for Diagnosis and prognosis of acute heart failure. Curr Emerg Hosp Med Rep. 2013;1(2)133-40.

35. Daniels LB, Maisel AS. Natriuretic peptides. J Am Coll Cardiol. 2007;18(50):2357-68.

36. Maisel A, Mueller C, Adams K Jr, Anker SD, Aspromonte N, et al. State of the art: using natriuretic peptide levels in clinical practice. Eur J Heart Fail. 2008;10:824-9.

37. - Maisel AS, Nakao K, Ponikowski P, Peacock WF, Yoshimura $\mathrm{M}$, Suzuki T, et al. Japanese-Western consensus meeting on biomarkers. Int Heart J 2011;53:253-65.

38. Lee SW, Song JH, Kim GA, et al. Plasma brain natriuretic peptide concentration on assessment of hydration status in hemodialysis patient. Am J Kidney Dis. 2003;41:1257-66.

39. Booth J, Pinney J, Davenport A. N-terminal proBNP-marker of cardiac dysfunction, fluid overload, or malnutrition in hemodialysis patients? Clin J Am Soc Nephrol. 2010;5:1036-40.

40. Marino R, Magrini L, Ferri E, Gagliano G, Di Somma S. B-Type natriuretic peptide and non-invasive haemodynamics and hydration assessment in the management of patients with acute heart failure in emergency department. High Blood Press Cardiovasc Prev. 2010;17:219-25.

41. Piccoli A. Identification of operational clues to dry weight prescription in hemodialysis using bioimpedance vector analysis. Kidney Int. 1998;53:1036-2043.

42. Piccoli A. Bioeletric impedance vector distribution in peritoneal dialysis patient with different hydration status. Kidney Int. 2004;65:1050-63.

43. Lukasky HC, Johnson PE, Bolonchuk WW. Assessment of fatfree mass using bioelectrical impedance measurements of human body. Am J Clin Nutr. 1985;41:810-7.

44. Kushner RF. Bioelectrical impedance analysis: a review of principles and applications. J Am Coil Nutr. 1992;11:119-209.

45. Talluri T, Lietdke RJ, Evangelisti A, Talluri J, Maggia G. Fat-free mass qualitative assessment with bioelectrical impedance analysis (BIA). Ann N Y Acad Sci. 1999;20:873-94.

46. Bosy-Westphal A, Danielzyck S, Dorhofer RP, Piccoli A, Muller MJ. Pattern of bioelectrical impedance vector distribution by body mass index and age: implication for body-composition analysis. Am J Clin Nutr. 2005;82:60-8.

47. Piccoli A. Identification of operational clues to dry weight prescription in hemodialysis using bioimpedance vector analysis. Kidney Int. 1998;53:1036-2043.

48. Bozzetto S, Piccoli A, Montini G. Bioelectrical impedence vector analysis to evaluate relative hydration status. Pediatr Nephrol. 2010;25:329-34.

49. •• Valle R, Aspromonte N, Milani L, Peacock FW, Maisel AS, Santini M, et al. Optimizing fluid management in patient with acute decompensated heart failure (ADHF): the emerging role of combined measurement of body hydration status and brain natriuretic peptide(BNP)levels. Heart Fail Rev 2011;16:519-29.

50. Piccoli A, Rossi B, Pilon L, Bucciante G. A new method for monitoring body fluid variation by bioimpedence analysis: the R/Xc graph. Kidney Int. 1994;46:534-9.

51. Stevenson LW, Perloff JK. The limited reliability of physical sign for estimating hemodynamics in chronic heart failure. JAMA. 1989;261:884-8.

52. •• Tuy T, Peacock WF. Fluid overload assessment and management in heart failure patients. Semin Nephrol. 2012;32(1): 112-20. This article underlines the importance of identifying and assessing fluid overload in critically ill patients. A rapid body water assessment, combined with clinical examination, can help the physician to improve the diagnosis and stratification of these patients and their clinical management. 
53. Di Somma S, Gori CS, Grandi T, Risicato MG, Salvatori E. Fluid assessment and management in the emergency department. Contrib Nephrol. 2010;164:227-36.

54. Bagshaw SM, Brophy PD, Cruz D, Ronco C. Fluid balance as a biomarker: impact of fluid overload on outcome in critically ill patients with acute kidney injury. Crit Care. 2008;12:169-72.

55. - Piccoli A, Codognotto M, Chanchi V, Vettore G, Zaninotto M, Plebani $\mathrm{M}$, et al. Differentation of cardiac and non cardiac dyspnea using bio-electrical impedance vector analysis. J Card Fail 2012;18:226-32.

56. •• Di Somma S, Lukaski HC, Codognotto M, Peacock WF, Fiorini F, Aspromonte N, et al. Consensus paper on the use of BIVA (bioelectrical impedance vector analisis) in medicine for the management of body hydration. Emerg Care J 2011;4:6-14.

57. Parrinello G, Paterna S, Di Pasquale P, Torres D, Fatta A, Mezzero M, et al. The usefulness of bioelectrical impedance analysis in differentiating dyspnea due to decompensated heart failure. J Card Fail. 2008;14:676-86.

58. Söderberg M, Hahn RG, Cederholm T. Bioelectric impedance analysis of acute body water changes in congestive heart failure. Scand J Clin Lab Investig. 2001;61:89-94.
59. Pillon L, Piccoli A, Lowrie EG, Lazarus JM, Chertow GM. Vector length as a proxy for the adequacy of ultrafiltration in hemodialysis. Kidney Int. 2004;66:1266-71.

60. Valle R, Aspromonte N, Giovinazzo P, Carbonieri E, Chiatto M, di Tano G, et al. B-Type natriuretic peptide-guided treatment for predicting outcome in patients hospitalized in sub-intensive care unit with acute heart failure. J Card Fail. 2008;14:219-24.

61. Di Somma S, Gori CS, Salvatori E. How to manage cardiorenal syndrome in the emergency room. Contrib Nephrol. 2010;165: 93-100.

62. - Ronco C, Kaushik M, Valle R, Aspromonte N, Peacock WF. Diagnosis and management of fluid overload in heart failure and cardio-renal syndrome: the "5B" approach. Semin Nephrol. 2012;32(1):129-41.

63. - Aspromonte N, Cruz DN, Ronco C, Valle R. Role of bioimpedance vectorial analysis in cardio-renal syndromes. Semin Nephrol. 2012;32(1):93-9.

64. Piccoli A, Pittoni G, Facco E. Relationship between central venous pressure and bioimpedance vector analysis in critically ill patients. Crit Care Med. 2000;28:132-7. 